\title{
Bricolagem da memória: fontes orais e visuais na construção da identidade agudá*
}

\author{
Milton Guran**
}

Neste texto retomo as conclusóes da minha tese $\mathrm{e}^{1}$ sobre o processo de construção da identidade social dos agudás - africanos escravizados no Brasil que retornaram à África ao longo do século XIX - no Benim e no Togo, atualizando-as à luz das pesquisas desenvolvidas desde então. $\mathrm{O}$ ponto central em análise é a utilização, por parte desses indivíduos, da memória do tempo vivido no Brasil - o que significa da memória da experiência da escravidão - como matéria-prima de um processo de bricolagem que tornou

* Este texto é, em parte, resultado de uma pesquisa que se desenvolve no âmbito do Projeto Universal do $\mathrm{CNPq}$ (Conselho Nacional de Desenvolvimento Científico e Tecnológico) intitulado Sons e imagens da rememoração: narrativas e registros das identidades e alteridades afro-brasileira nos séculos XIX e XX, em curso; a investigação contou, ainda, com apoio da FAPERJ (Fundação de Amparo à Pesquisa do Rio de Janeiro), através do projeto Memórias, identidades e alteridades afro-brasileira nos séculos XIX e XX: imagens e sons da rememoração (2008-2010). Ambos os projetos são coordenados pela Prof. ${ }^{a}$ Ana Maria Mauad, pesquisadora do Laboratório de História Oral e Imagem da Universidade Federal Fluminense (LABHOI/UFF).

O processo de construção da identidade social agudá no Benim é analisado por mim de forma mais completa no livro Agudás: os "brasileiros" do Benim (Guran, 2000). Acerca dos agudás, ver também Almeida Prado (1954), Braga (1968), Castro (1965), Costa e Silva (1989a, 1989b, 1989c, 1994, 2003 , 2004), Cunha (1985a, 1985b), Freyre (1990), Krasnowolski (1987), Law (2004), Rodrigues (1962), Rossi (1965), Turner (1975), Verger (1953a, 1968, 1992).

** Antropólogo, professor visitante do Programa de Pós-Graduação em História da Universidade Federal Fluminense (PPGH/UFF) e pesquisador associado do LABHOI/UFF.

1 Tese de doutorado em antropologia intitulada Agoudás: Les "Brésiliens" du Bénin - enquête anthropologique et photographique, realizada sob direção de Jean-Pierre Olivier de Sardan e defendida em 1996 na École des Hautes Études em Sciences Sociales (EHESS), em Paris, graças a uma bolsa de estudos da CAPES/MEC. 
possível a sua assimilação pelo grupo social dos negreiros então estabelecidos naquela região. Esse processo, que denominei bricolagem da memória, opera pela composição de um conjunto de referências históricas que foram passadas pela tradição oral e se inscrevem no presente por meio de rituais simbólicos e comportamentos sociais - maneiras de se vestir, se alimentar e falar que identificam os agudás entre si e os diferenciam dos demais grupos. Dessa forma, esses ex-escravos se reinseriram como cidadãos com plenos direitos na própria sociedade que os tinha excluído, o que é bastante raro.

Dentre os diversos marcadores de identidade utilizados pelos agudás, destacam-se a representação de si e a utilização residual da língua portuguesa. Esses dois aspectos são principal foco do projeto Falares luso-brasileiros no Benim - desenvolvido no âmbito das minhas atividades como pesquisador do LABHOI/UFF -, baseado principalmente na observação apoiada em fotografias, vídeos e entrevistas, como forma de enfatizar a presença da língua e os usos do passado pelo presente como estratégia nesse processo permanente de construção de identidade social.

Agudá é o termo pelo qual são designados em iorubá, fon e mina os beninenses que possuem sobrenome de origem portuguesa ou são oriundos de famílias com essa origem. A palavra agudá provavelmente é uma transformação da palavra “ajuda”, nome português da cidade de Uidá. Essa palavra era muito conhecida da região por causa do forte português de Uidá, chamado de Forte São João Baptista da Ajuda. ${ }^{2}$ Em francês, a língua corrente no Benim desde a implantação da administração colonial francesa no final do século XIX, os agudás são chamados e chamam a si próprios simplesmente de "brésiliens", entre aspas quando por escrito. ${ }^{3}$

Apesar de estarem completamente inseridos na trama social do Benim e do Togo, os agudás guardam diferenças sutis dos demais grupos sociais. Um dos comentários mais recorrentes entre os agudás diz que "Um fon 'evoluído,

2 Paul Hazoumé (1937, p. 35) apresenta a palavra agouda como uma transformação da palavra fon ou huéda (língua original da cidade de Uidá) agouram, que, segundo ele, designaria os europeus "vaidosos e indolentes”. Essa versão, entretanto, não me parece compatível com outros dados históricos disponíveis e não é retomada por nenhum outro autor, razões pelas quais preferi considerar a explicação corrente até os nossos dias (Cf. Braga, 1968).

3 Já há algum tempo, cientistas sociais beninenses começam a utilizar a expressão afro-brésiliens para designar os agudás. Prefiro, no entanto, empregar a expressão já consagrada - "brasileiros" - para não confundir com o adjetivo relativo à cultura africana da diáspora nas Américas e, sobretudo, porque "brasileiros" é o termo endógeno utilizado por todas as populações envolvidas - o que representa, em si, um importante fator de afirmação de uma identidade social. 
atualmente, é semelhante a um agudá. Mas, quando você olha bem de perto, vê que um 'brasileiro' é sempre um 'brasileiro'”, referindo-se à maneira específica dos agudás de se apresentarem socialmente de acordo com os códigos de comportamento da sociedade ocidental.

Os agudás do Benim e do Togo têm origens diversas e se encontram atualmente em todas as classes sociais; são católicos, na maioria, ou muçulmanos. A maior parte deles, sem dúvida, é constituída por descendentes de traficantes ou de comerciantes brasileiros ou portugueses estabelecidos nessa costa, ou ainda por descendentes de antigos escravos retornados do Brasil - a estes, se somam os descendentes dos escravos dos agudás do século XIX. Os africanos escravizados no Brasil que retornaram ao Benim tinham efetivamente vivido um processo de socialização urbana; na qualidade de serviçais domésticos (ou de escravos de ganho, p. ex.), sua vida cotidiana era bastante próxima da de seus senhores. A sua referência cultural se situa, portanto, entre os seus senhores e não somente nas camadas mais populares - é o comportamento das elites baianas que eles vão procurar reproduzir na África.

Foi no Benim que a cultura brasileira deitou as suas mais fortes raízes ainda hoje, podemos encontrar aspectos evidentes materializados em sobrenomes, construções (as mais antigas do país), comidas típicas, festas e até no tom de pele dos agudás, mais claro que o dos demais beninenses. Entretanto, outros aspectos podem ser, ao primeiro olhar, menos evidentes ou mesmo invisíveis, a despeito da sua importância; é o caso da maneira de se apresentar ou se vestir, receber as visitas, se comportar à mesa, ou ainda da organização doméstica e da educação das crianças - para citar apenas alguns exemplos.

A construção da nova identidade social que permitiu a inserção desse grupo de retornados na sociedade africana em transformação estava fundamentada na oposição entre as noções de "civilização/modernidade" e "primitivismo/selvageria”. Essa equação toma corpo no fato de que, pelos autóctones da época do retorno (e até os nossos dias), os "brasileiros” eram sempre considerados "escravos" ou, na expressão regional, "gente importada"; enquanto que os autóctones são tratados sempre como "selvagens" pelos "brasileiros". Todos os agudás entrevistados, ${ }^{4}$ sem exceção, afirmaram ter sido tratados de escravos e de gente importada pelos outros africanos que se dizem do pais. Estes últimos se defendem dizendo que apenas reagem à qualificação de selvagens

4 Pesquisa de campo no Benim e Togo efetuada de forma intensiva de 1994 a 1996, que prossegue até os dias hoje. 
que lhes é dada pelos agudás. A confrontação se dá, sobretudo, na escola e no mercado, locais onde existe naturalmente uma situação de concorrência.

Nas sociedades marcadas pela memória da escravidão "as relações (entre os povos raptores e os povos agredidos) se mantêm sobre a base do não-reconhecimento dos exotismo e perpetuam uma alteridade irredutível" - explica Meillassoux (1986, p. 74). Assim sendo, "esta relação de alteridade" - acrescenta ele - "é na verdade a explicação ideológica de uma relação de dominador e dominado que opõe o conjunto dos cidadãos livres das sociedades escravagistas ao conjunto das populações agredidas, puncionadas no passado, no presente e no futuro". É precisamente essa relação entre dominador e dominado que os antigos escravos vão subverter através da construção de uma nova identidade, sem, no entanto, conseguir apagar completamente as relações de alteridade que são justamente irredutíveis.

A representação de si é um dos aspectos mais evidentes da construção de uma identidade..$^{5}$ A partir do fato de que este processo se tornou perene, podemos seguir-lhe os traços ainda visíveis até os nossos dias, por exemplo, nos retratos dos ancestrais fundadores das famílias agudás - expostos no interior das casas, conforme o costume do país -, que apresentam sempre senhores vestidos à europeia: uma espécie de atestado da sua condição de "evoluídos", antes mesmo que os franceses tivessem imposto as "maneiras de branco" por meio da colonização.

O retrato, como se sabe, é a definição visual de um indivíduo, a imagem que ele escolheu para representá-lo pessoalmente e socialmente. Além do mais, mandar fazer seu retrato, como observou Gisèle Freund (1974, p. 11), é "um desses atos simbólicos pelos quais os indivíduos da classe ascendente tornam visíveis a eles mesmos e aos outros sua ascensão e se classificam entre aqueles que desfrutam da consideração social”. Um dos casos mais emblemáticos é o retrato do fundador da poderosa família De Souza - Francisco Félix de Souza, o Chachá I -, que domina a galeria de retratos da sua antiga residência, chamada Singbomey, em Uidá. ${ }^{6}$ Trata-se de um retrato póstumo, pintado a óleo, que representa o fundador da família com ares de aventureiro, portando um boné com pendente e um lenço no pescoço, um pouco ao

5 Cf. Bourdieu (1965) e Goffman (1973).

6 O negreiro baiano Francisco Félix de Souza tornou-se irmão de sangue do rei Guêzo, do Daomé, e recebeu deste o título de Chachá, com status de vice-rei. Cf. Guran (2000). 
modo de Giuseppe Garibaldi na sua imagem mais conhecida. É, digamos, a sua foto oficial, que vem sendo atualizada nos últimos anos.

O retrato original apresenta um homem com feições bem-desenhadas, vasta barba sobre tez amorenada, cabelos longos emoldurando uma expressão séria, com olhar duro. É a imagem de um aventureiro, acima de tudo um desbravador, "construtor de impérios". Esse retrato foi reproduzido por Verger na década de $1950^{7}$ e é o mesmo que encontrei em Singbomey quando da minha primeira visita, em 1994 (Foto1).

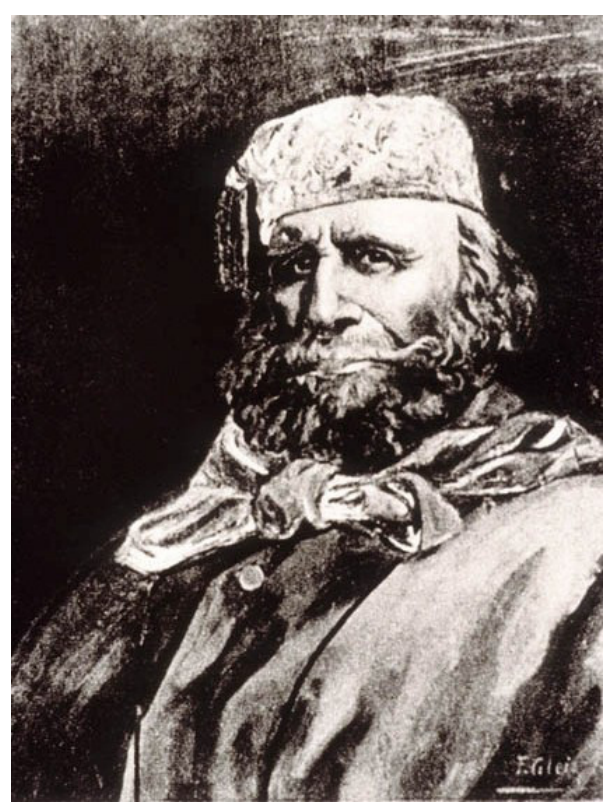

Foto 1 - Retrato de Francisco Félix de Souza, o Chachá I, em Singbomey, Uidá, 1996 (reprodução de Milton Guran).

Já em 1996, por ocasião da entronização do Sr. Honoré Feliciano Julião de Souza como Chachá VIII - em cerimônia presidida pelo homem mais idoso da família, o Sr. Marcelin de Souza -, o personagem tinha sido ungido por uma espécie de aura, como na representação dos santos católicos (Foto 2), embora guardasse ainda as mesmas expressões do retrato original.

7 Consultar Verger (1968, imagem 24). 


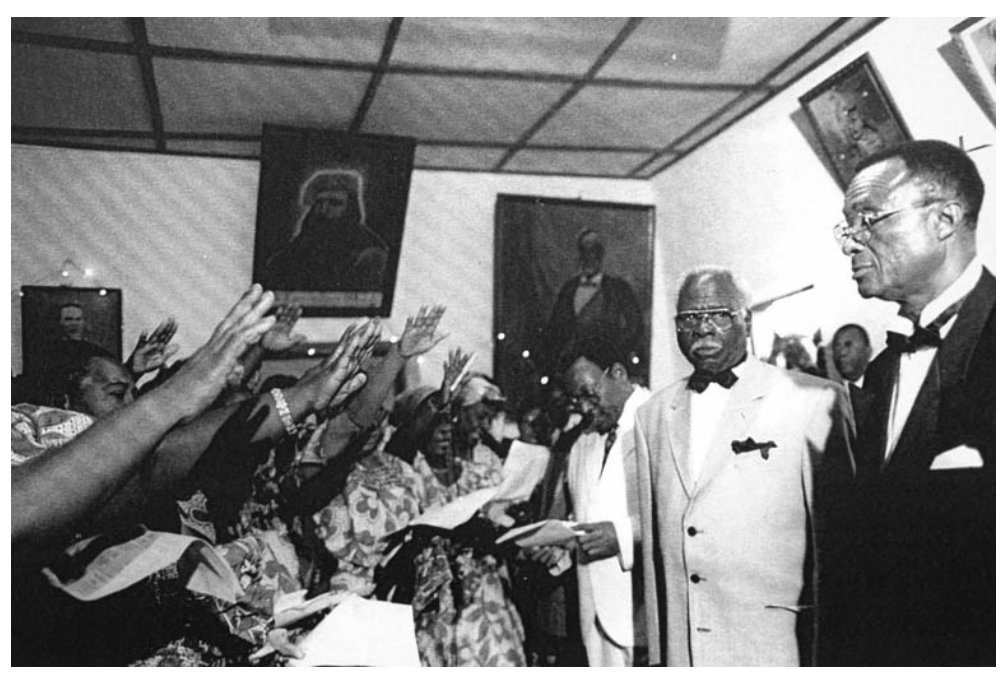

Foto 2 - A família De Souza saúda o novo Chachá, à direita na foto, em cerimônia presidida por Marcelin de Souza, de paletó branco (foto de Milton Guran).

Cabe ressaltar que Honoré Feliciano de Souza apresenta-se vestido da mesma forma que o seu avô Julião Feliciano de Souza, o Chachá IV (Foto 3). Uma vez entronizado, ele complementou seu traje oficial com um barrete semelhante ao do bisavô e uma espécie de capilha de veludo vermelho, em alusão ao lenço que o fundador da família portava em volta do pescoço, segundo o seu retrato oficial. 


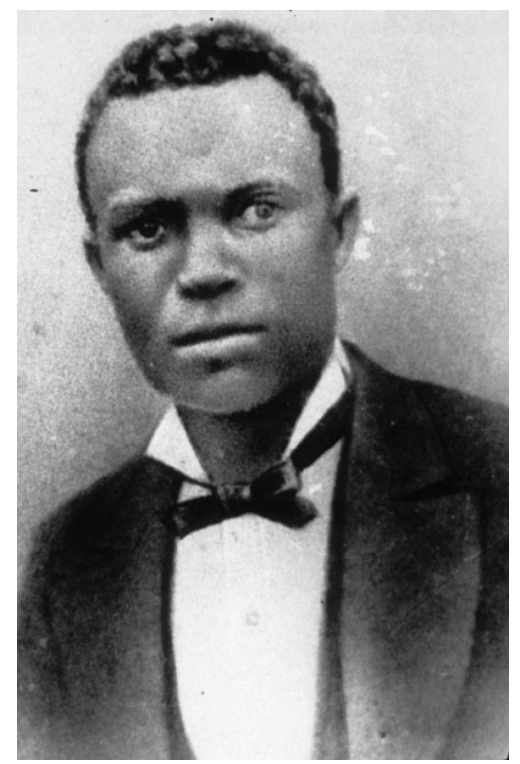

Foto 3 - O Chachá IV em retrato exposto junto a seu túmulo, em Singbomey, Uidá, 1994 (reprodução de Milton Guran).

Ao se apresentar dessa forma, o Chachá VIII buscava legitimar-se aos olhos de todos, sinalizando visualmente o seu pertencimento à dinastia e, mais especificamente, ao ramo do Chachá IV, que havia sido acusado de traição e executado pelo rei do Daomé em 1887 (Guran, 2000, p. 185-194).

Essa estratégia de recuperar signos visuais pertencentes à dinastia, na verdade, já tinha sido usada pelo Chachá III, Francisco "Chicou” de Souza. Como podemos observar na Foto 4, onde aparece à direita, ele se fez representar com o barrete do pai, mas com uma vestimenta semelhante à do seu irmão mais velho, Isidoro de Souza, o Chachá II, que tinha estudado na Bahia e, por sua vez, buscou caminho próprio, apresentando-se como um burguês de tinturas aristocráticas, bem ao gosto da época (Guran, 2000, p. 173-185).

Recentemente, por ocasião da criação de uma fundação com seu nome, dedicada a guardar e glorificar a sua memória e gerir o patrimônio simbólico da família, seu retrato foi novamente "atualizado" (Foto 4). 


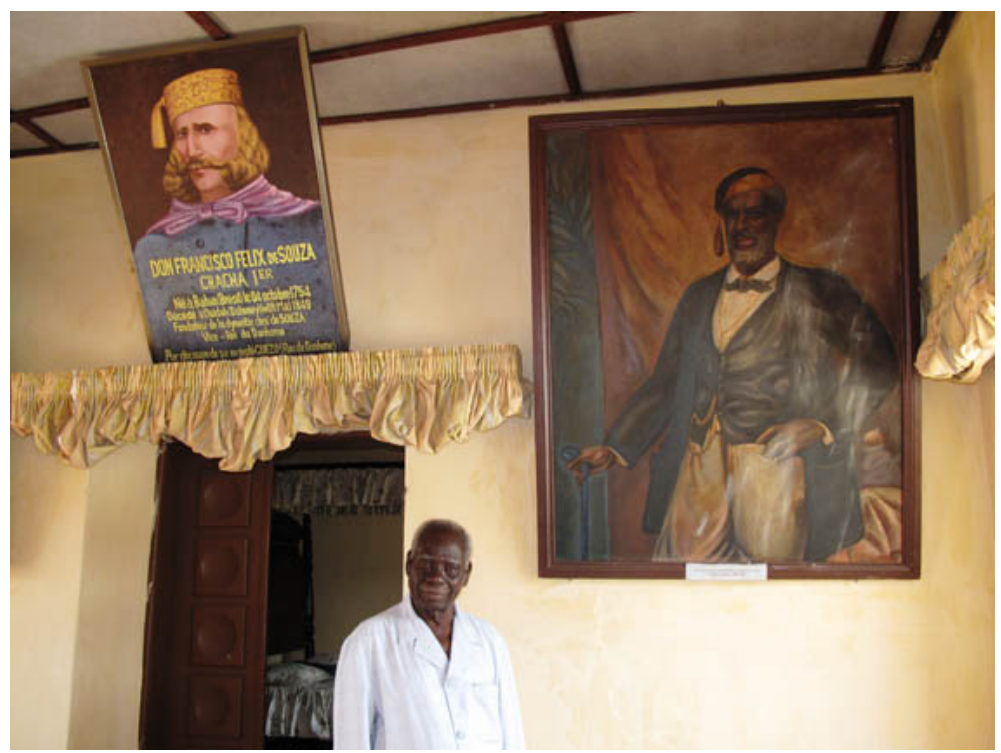

Foto 4 - Sr. Marcelin de Souza no salão principal de Singbomey, diante dos retratos do Chachá I e do Chachá III.

Dom Francisco aparece rejuvenescido, com os cabelos alourados e frisados, queixo barbeado, mas ostentando portentosos bigodes e suíças fartas, também alourados. Seu olhar ficou mais curioso do que duro e o lenço à volta do pescoço, que era vermelho no retrato original, tornou-se mais suave em um moderno tom de lilás. Deixou de ser o destemido "construtor de impérios" para se afirmar como um simpático aventureiro que fundou uma vasta família na África.

A representação de si - materializada em retratos expostos na entrada das casas em todos os níveis sociais - permite aos "brasileiros" estabelecer de imediato uma fronteira nítida marcando as suas diferenças em relação ao conjunto da sociedade. $\mathrm{O}$ fato de que essas fotos estejam em exibição na sala de entrada da casa exprime bem a importância de manter bastante em evidência essa "diferença desde as origens" e de alimentá-la sempre.

A ideia de que existe uma memória coletiva agudá relativa a um patrimônio cultural comum a preservar está presente em diversos níveis tanto no discurso quanto na vida cotidiana dos "brasileiros". À memória do tempo passado no Brasil, tão caro aos antigos escravos retornados (e que, aliás, lhes 
serviu de matéria-prima para a construção da nova identidade social), se acrescenta atualmente a memória da própria construção dessa identidade.

Afirmações como "nós fizemos tudo neste país" e "nos orgulhamos muito dos nossos ancestrais" aparecem invariavelmente nos discursos quando se trata da questão étnica. Eles destacam desse modo o fato de que têm um passado importante de realizações para honrar, o que constitui para eles um fator de diferenciação e lhes permite estabelecer uma fronteira étnica diante de outros grupos sociais. Esse passado é comum aos descendentes de negreiros e aos antigos escravos retornados e seus antigos escravos no país: "A folha que durante muito tempo enrolou o sabão ensaboa como o sabão...", costuma-se dizer no Benim. Entretanto, sob determinadas condições, os descendentes dos traficantes brancos - que no fundo se veem como os verdadeiros "brasileiros" - reivindicam uma certa supremacia em relação aos outros.

Ao lado, portanto, da memória das realizações existe a de uma maneira de ser diferente que a complementa e que reforça atualmente a fronteira cultural entre os agudás e o resto da população. Essa maneira de ser diferente não quer dizer exatamente ter "maneiras de branco", como ocorreu na época do retorno. Já que a colonização vulgarizou por todo o país as "maneiras de branco", os agudás reivindicam uma particularidade própria, a de ter "maneiras 'brasileiras' de branco". Eles afirmam essa particularidade na maneira de se apresentarem, de se saudarem, na culinária, na condição de primeiros católicos, na pronúncia portuguesa de seus nomes, no emprego de algumas palavras e expressões em português na conversação entre si - essas palavras e expressões são conhecidas por praticamente todos os agudás, incluindo os jovens.

Essa maneira de ser "brasileiro" é naturalmente calcada nas reminiscências do que é ser brasileiro no imaginário do grupo, permanentemente reforçadas por posturas individuais e ações públicas que expressam de forma clara o pertencimento. Assim é que eles reivindicam um "traje tradicional", que inclui o uso da gravata para os homens e de saias compridas para as mulheres, à moda do Segundo Império, que foi quando os fundadores das atuais famílias atravessaram o Atlântico de volta às origens. Também esse

8 Essa lógica é por vezes levada a extremos. Encontrei, entre descendentes de traficantes, indivíduos que se consideram cidadãos brasileiros - e que têm esperanças de ver essa condição reconhecida um dia pelo governo brasileiro -, e outros que se consideram efetivamente "brancos que têm a pele negra", já que seus ancestrais foram obrigados a casar-se com mulheres negras. 
figurino vem sendo progressivamente "atualizado": na Foto 5, por exemplo, vemos a Sra. Amégan, cujo sobrenome de família é Campos, ${ }^{9}$ em traje típico das mulheres agudás por ocasião das celebrações de Nosso Senhor do Bonfim em Porto Novo em 1995.

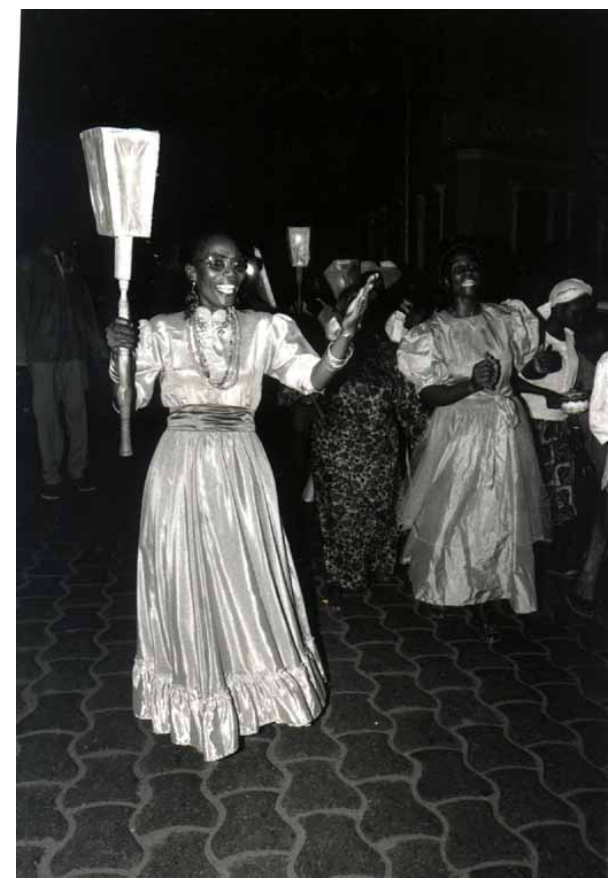

Foto 5 - Mme. Amégan no desfile das celebrações de Nosso Senhor do Bonfim, em Porto Novo, 1995 (foto de Milton Guran).

Esse vestido usado pela Mme. Amégan, por sua vez, já era uma releitura do traje original feita a partir dos figurinos apresentados pela novela Demoiselle, versão em francês de Escrava Isaura, da TV Globo, que fez enorme sucesso em toda a África Ocidental na década de 1990 (Guran, 2000, p. 125). Esse tipo de roupa foi atualizado também para uso cotidiano, como vemos na Foto 6, por ocasião de uma gravação do projeto Falares luso-brasileiros

9 Eucharistes Campos, fundador da família, entrou para a história do Benim ao sugerir ao rei de Porto Novo esse nome para o reino, já que o original era impronunciável para os brasileiros (Guran, 2000, p. $\mathrm{XX})$. 
no Benim e no Togo. Nesta foto, a Mme. Amégan aparece ao lado de uma senhora trajada à moda tradicional africana, o que nos permite ver bem a distinção identitária na representação de si.

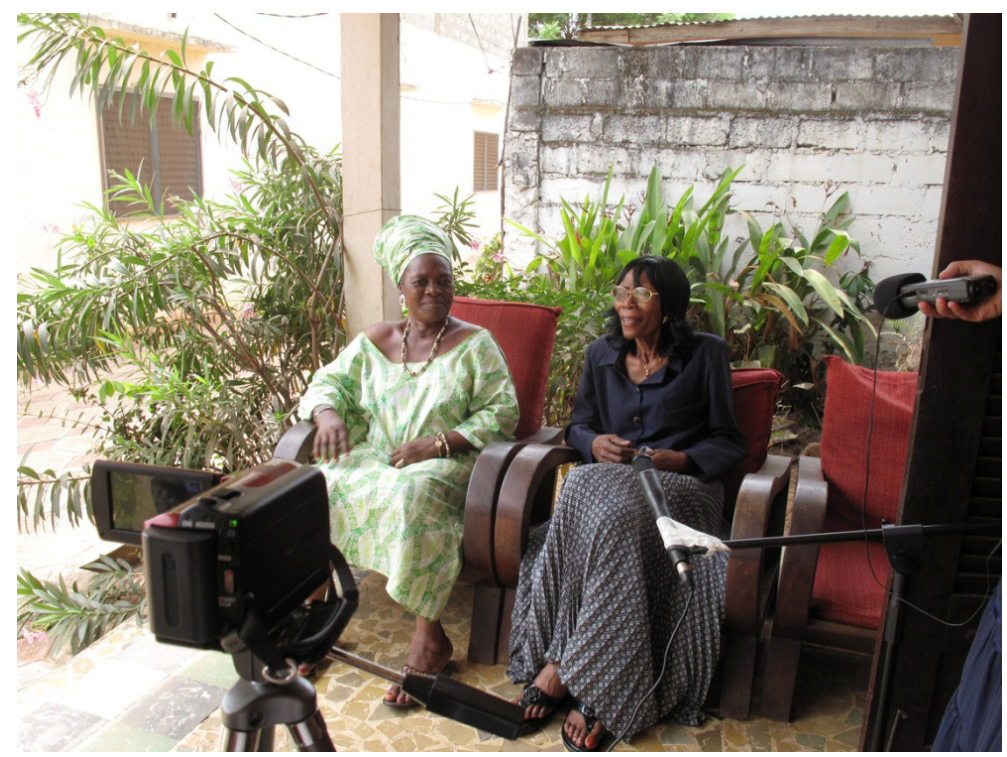

Foto 6 - Mme. Amegan em sua residência, em Porto Novo, 2010 (foto de Milton Guran).

$\mathrm{Na}$ verdade, ao se apresentar vestida com esmero, portanto de saia comprida e com o cabelo perfeitamente alisado, Mme. Amégan segue à risca o figurino da aristocracia agudá, à qual ela pertence, marcando a diferença em relação às demais mulheres agudás. 


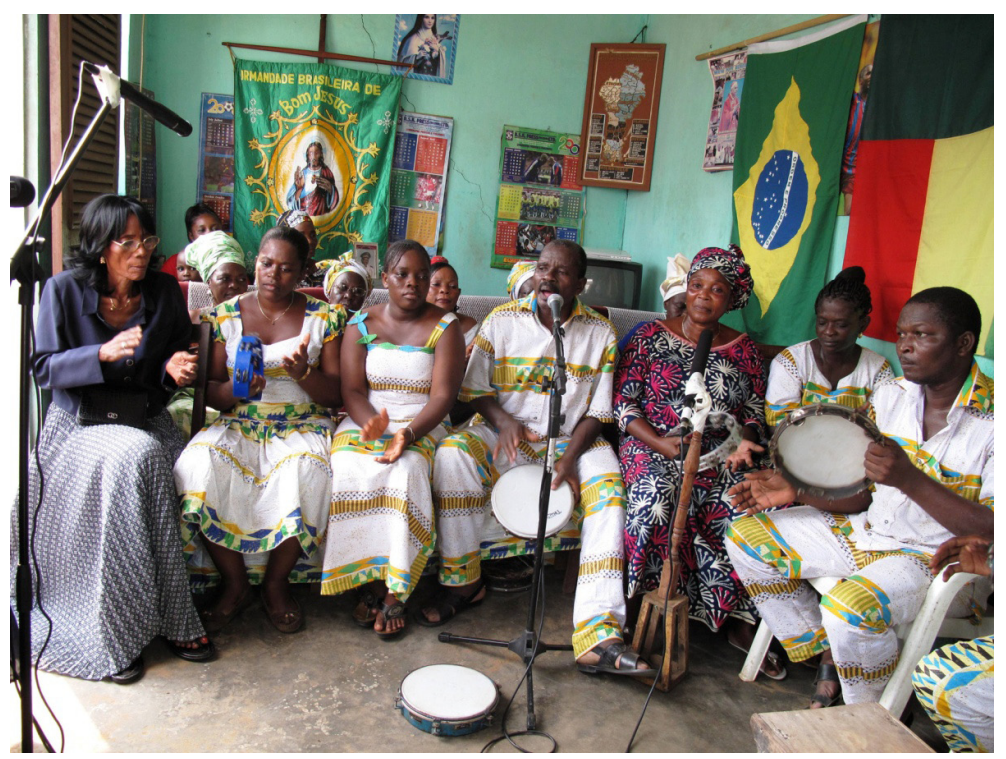

Foto 7 - Ensaio de canções da "burrinha" na residência da família Amaral, em Porto Novo, 2010 (foto de Milton Guran).

De fato, as mulheres agudás, nas mesmas circunstâncias, evitam os trajes africanos tradicionais; preferem modelos ocidentais mais modernos, como podemos observar nessa cena de um ensaio do repertório das canções da "burrinha”, tradicional folguedo agudá que abordaremos mais adiante (Foto 7).

Essa cena é bastante emblemática da identidade agudá. Vemos em primeiro plano um grupo homens e mulheres vestidos à ocidental, com exceção de uma única senhora que se apresenta em trajes africanos. Trata-se de Antoinette Campos (da mesma família que Mme. Amégan), figura proeminente do grupo por ser tida como a melhor cantora - aquela que, inclusive, conhece o maior número de canções em português. Também em primeiro plano aparece um pandeiro, instrumento emblemático que chegou à África pelos agudás, que por sua vez o conheceram no Brasil, para onde veio trazido pelos portugueses que o receberam dos árabes. Ao fundo, encontramos todo um repertório de símbolos dessa bricolagem identitária, que se reivindica brasileira e beninense ao mesmo tempo. A presença de ícones católicos, sendo o maior deles o estandarte da Irmandade Brasileira de N. S. do Bonfim, do qual trataremos mais adiante, marca a tradição brasileira (os agudás já eram 
católicos quando chegou por lá a Missão católica de Lyon), ao lado do mapa da República do Benim e das duas bandeiras nacionais.

O Sr. Bruno Rodrigues (1996), da cidade de Bohicon, quando perguntado sobre o que caracteriza os agudás nos dias de hoje, respondeu que eles tinham entre si uma "maneira de fazer as coisas" diferente, uma memória comum composta de lembranças compartilhadas por todos os agudás. Marceneiro de profissão, aos 70 anos ele é, talvez, o maior conhecedor do folguedo da burrinha na região, e o último especialista na fabricação dos bonecos do espetáculo. "Temos lembranças que são só nossas" - me diz ele -, "histórias do passado e também maneiras de falar e de se saudar...". Eu o interrompo, em português: "Como passou?", e ele responde de pronto: "Bem, 'brigado”.

Essa representação de si "à brasileira” está presente em todas as situações em que a identidade agudá é posta em evidência, sendo expressamente usada para esse fim - é o caso das festividades de Nosso Senhor do Bonfim, o padroeiro dos agudás, celebradas sempre no mês de janeiro, principalmente nas cidades de Uidá e Porto Novo.

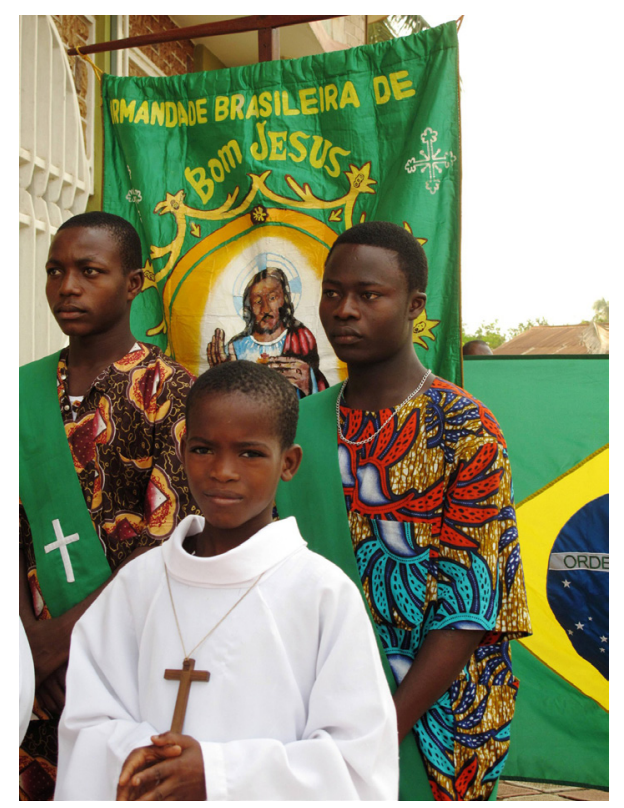

Foto 8 - Missa de Nosso Senhor do Bonfim na Igreja do Sagrado Coração de Porto Novo, janeiro de 2010 (foto de Milton Guran). 


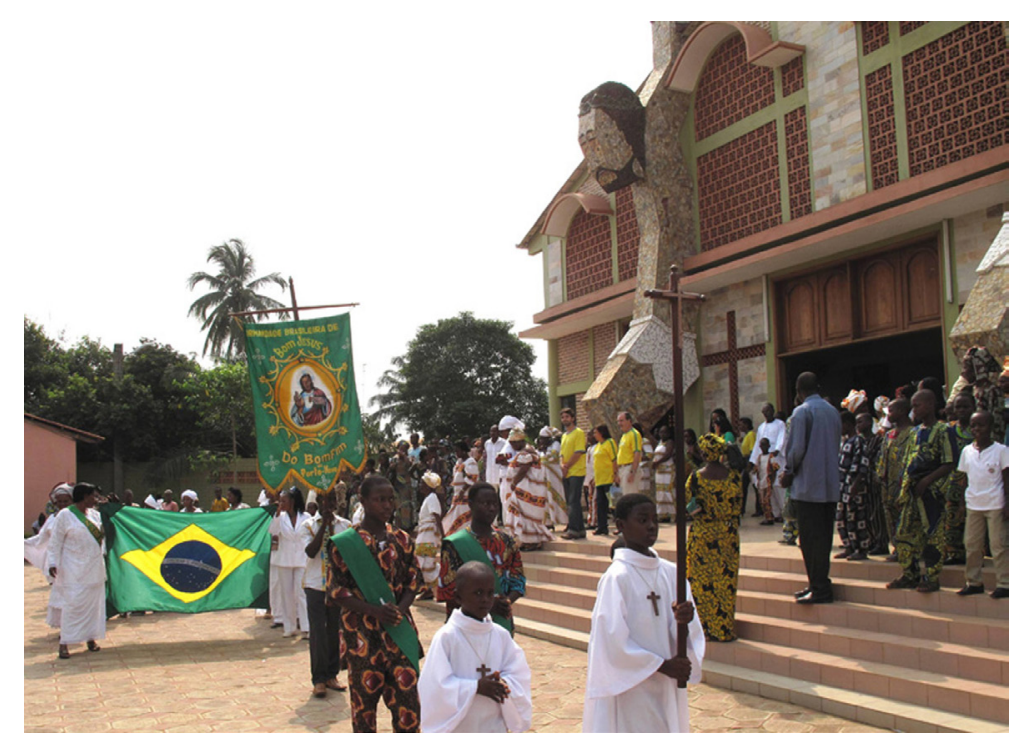

Foto 9 - Cortejo na entrada da Missa de Nosso Senhor do Bonfim na Igreja do Sagrado Coração de Porto Novo, janeiro de 2010 (foto de Milton Guran).

O ponto alto da celebração de Nosso Senhor do Bonfim é a missa solene que a Irmandade Brasileira do Bom Jesus do Bonfim de Porto Novo manda rezar - prestigiada por agudás de todas as classes sociais que comparecem nos seus melhores trajes. A programação é praticamente a mesma que foi observada por mim há vinte anos (Guran, 2000, p. 125 e ss.). A entrada na igreja é em cortejo, aberto pelo estandarte que é seguido pela bandeira nacional brasileira e por todos os agudás, de forma solene (Fotos 8 e 9).

São dois desfiles pelas ruas da cidade, um no sábado que antecede a missa do Bonfim e outro na saída da missa. Em ambos, a identidade "brasileira" é enfatizada pela utilização de símbolos efetivamente brasileiros, como a bandeira nacional, e também pelo uso de trajes típicos - os homens de gravata e as mulheres de vestido longo. Os dignitários da Irmandade portam faixas com a inscrição "N. S. do Bonfim", com a grafia da língua portuguesa, e não em francês, a língua oficial do país; é o caso de Mme. Martins, descendente do negreiro Domingos José Martins, filho homônimo de um dos líderes da Revolução Pernambucana de 1817 (executado por D. Maria I e laureado como herói da Independência pelo seu neto, D. Pedro I) (Guran, 2000, p. 34-45; Rossi, 1965), que aparece no primeiro plano da Foto 10. 
Eles percorrem várias ruas cantando canções em português, como a que tem como refrão: "A sociedade brasileira está rua / venha ver / venha brincar / o brinquedo é delicado / para quem / para quem sabe brincar". A palavra "brasileira", talvez a única cujo significado todos conheçam, é enfatizada a plenos pulmões (Foto 10).

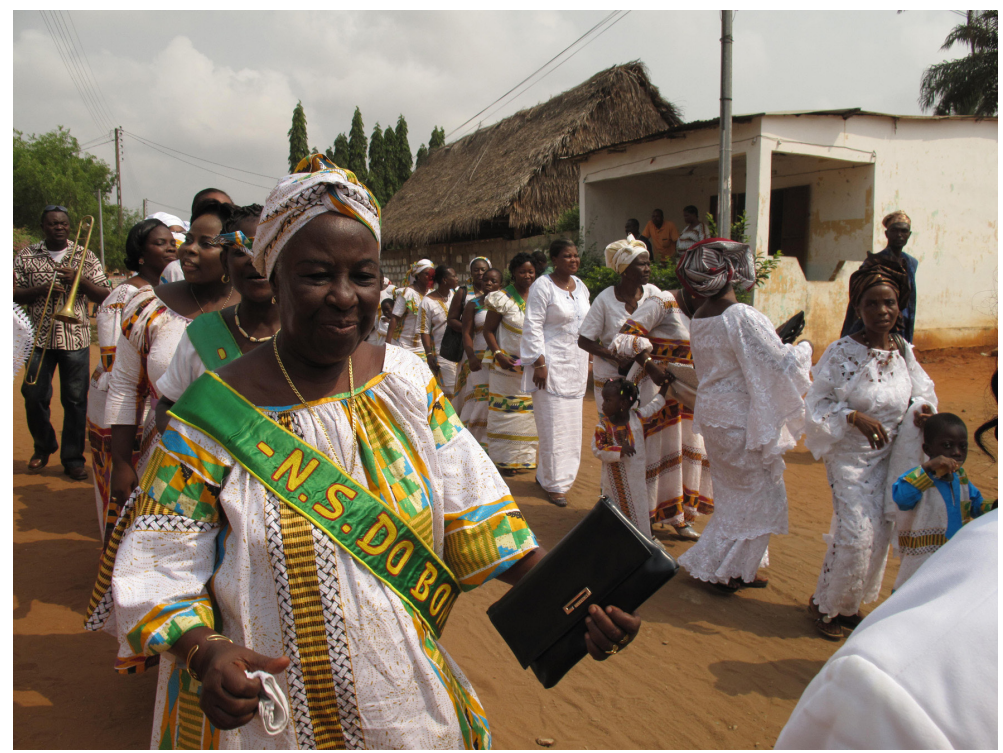

Foto 10 - Mme. Martins no desfile de Nosso Senhor do Bonfim, em janeiro de 2010 (foto de Milton Guran).

Nesse desfile, bastante descontraído e semelhante por vezes ao carnaval brasileiro, incorporam-se personagens da burrinha, folguedo bastante popular na Bahia do século XIX que praticamente desapareceu no Brasil, mas sobrevive no Benim. A apresentação da burrinha é a parte final da celebração, e acontece normalmente em um espaço aberto, com a participação de um público que vai além da comunidade agudá. Em 2010, a apresentação da burrinha manteve a mesma estrutura que observei vinte anos antes, com os mesmos personagens e as mesmas canções, animadas por um grupo de músicos sob a liderança da família Amaral, há décadas o principal motor do folguedo (Guran, 2000, p. 152-172). Também nesse momento vê-se a mesma atualização de signos que se observa em relação aos retratos da família De Souza, o que mostra como a identidade vai se adaptando e se reconstruindo para não 
deixar de ser o que é. O figurino feminino se moderniza na medida em que as referências ao Brasil também se atualizam pela televisão e pelas redes sociais; está mais leve e descontraído, embora mantenha o comprimento das saias e o uso do chapéu, um símbolo de distinção “à brasileira” (Foto 12).

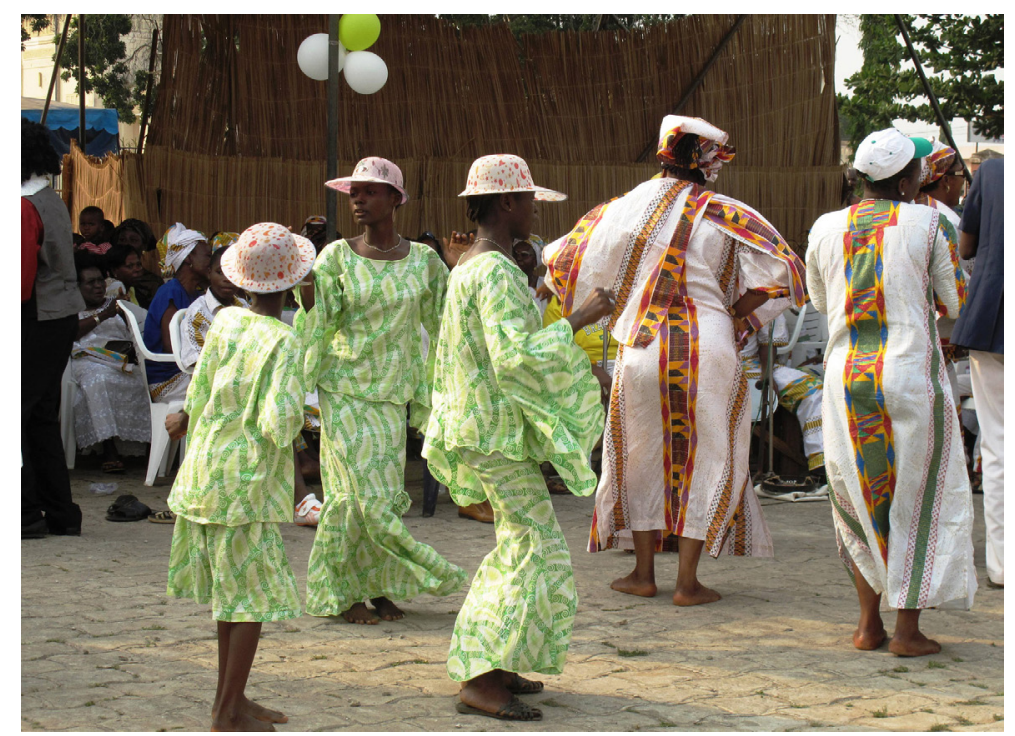

Foto 12 - Mulheres agudás dançam o "samba" no folguedo da burrinha em Porto Novo, 2010 (foto de Milton Guran).

Nesse ano, a embaixada do Brasil apoiou a realização da celebração, o que permitiu aos agudás confeccionarem roupas com o mesmo tecido, com as cores brasileiras, para todos os integrantes da burrinha. Houve farta distribuição de camisetas brasileiras, como a que podemos ver vestindo Antoinette Campos (que já conhecemos da Foto 7), ao lado de Auguste Amaral na Foto 13. A Foto14, por sua vez, nos mostra uma burrinha bastante modernizada, feita de material mais leve e mais colorida que a tradicional. 




Foto 13 - Orquestra da Burrinha, Porto Novo, 2010 (foto de Milton Guran).

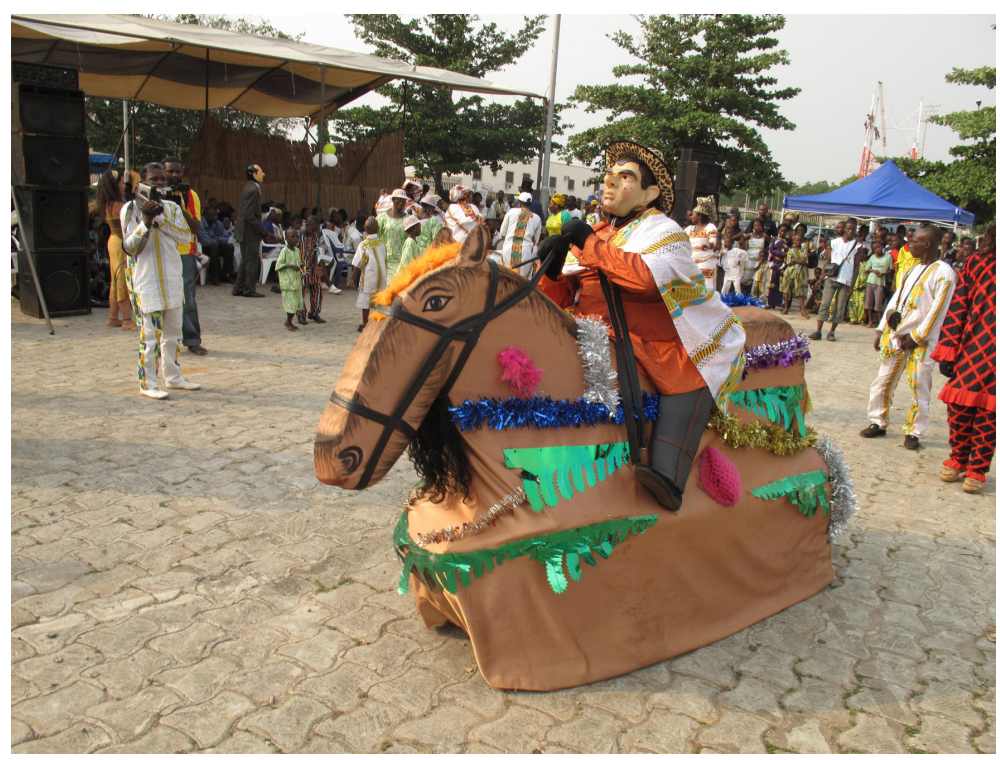

Foto 14 - A burrinha de Porto Novo, em 2010 (foto de Milton Guran). 
Ser agudá no Benim, até hoje, significa compartilhar uma memória relativa a um conjunto de realizações e a uma maneira de ser "à brasileira". Para melhor compreensão, podemos dividir o processo de construção dessa identidade social em três períodos sucessivos.

O primeiro começa no momento em que a presença dos negreiros brasileiros na Costa se torna mais forte, a partir do começo do século XIX. O tráfico de escravos já tinha sido proibido e os baianos tudo fizeram para assegurá-lo alguns anos mais. Esses traficantes e comerciantes brasileiros eram brancos que viviam à sua maneira e que se casaram com mulheres nativas. Eles mantinham relações comerciais e políticas com os autóctones, que eram de certo modo assimilados por meio do casamento. Não eram muito numerosos, apesar da sua grande importância econômica e política, e fizeram fortuna e viviam segundo sua própria cultura. Brancos em uma sociedade negra - os filhos mestiços eram considerados brancos como seus pais -, tratavam-se e eram por todos tratados de agudás, designação que remontava a várias gerações.

Um segundo momento é o da chegada maciça dos antigos escravos, a partir de 1835. Eles eram negros, mas tinham "maneiras de branco". Discriminavam os autóctones, que consideravam como "selvagens", assim como eram rejeitados por estes, para quem continuavam sempre a ser "escravos", ou seja, excluídos.

A questão da escravatura, praticamente ausente dos livros escolares e muito frequentemente minimizada nas obras eruditas sobre o antigo reino do Daomé, está, entretanto, sempre presente nas relações sociais e pessoais. De fato, como sublinha Meillassoux (1986, p. 107), "a captura (ou a compra que pressupõe a captura) marca os escravos de um estigma inapagável”. O tráfico na região foi inclusive o motor da economia durante séculos, e a escravatura sempre tinha sido uma instituição entre todos os povos envolvidos. Não é de estranhar, portanto, que a discriminação social fundamentada na condição de ter sido escravo continue muito presente nas relações dos agudás entre si e com os outros grupos sociais.

Como disse, todos os "brasileiros" que entrevistei ao longo da minha pesquisa afirmaram ter sido apontados e chamados de escravos em várias situações da vida cotidiana - é praticamente a regra na escola e no mercado. No domínio da vida privada, pelo contrário, como explica o historiador François de Medeiros, "há um acordo tácito para não se falar jamais de ascendência escrava" (Medeiros, 1996). 
Os antigos escravos que retornaram tinham diferentes origens étnicas e só estavam unidos pelo passado comum vivido no Brasil. Em outras palavras, o que os unia era a memória comum de uma experiência social vivida. Essa memória se traduzia por uma prática de vida, uma maneira de ser e, sobretudo, por uma qualificação profissional condizente com os novos parâmetros culturais e econômicos europeus que se impunham cada vez mais no país. Eles usavam sobrenomes de branco e tinham como modelo a cultura dos brancos adquirida no Brasil. Essa cultura foi um grande trunfo e lhes permitiu se associarem aos negreiros baianos nas atividades econômicas mais modernas. Primeiramente baseadas no tráfico de escravos, essas atividades evoluíram rumo a um comércio internacional e local mais variado, bem como à produção e exploração de recursos locais, como o óleo de palma ou dendê.

Para o conjunto da sociedade, eles tinham "maneiras de branco", diziam-se católicos e falavam português. Seu número - aumentado pelos escravos nativos a seu serviço - foi se tornando mais expressivo e, em consequência, eles foram adquirindo progressivamente um peso maior na demografia da região. Formavam uma comunidade, na qual os primeiros brancos e seus descendentes mestiços eram uma espécie de elite. Durante a segunda metade do século XIX, eles constituíram uma sociedade à parte, basicamente endogâmica, ${ }^{10} \mathrm{e}$ construíram uma identidade social assimilada à dos primeiros brasileiros. Essa identidade se reproduzia também por meio da religião - eles eram basicamente católicos, apesar da mistura com os cultos vodus - e da instrução escolar. Criaram escolas onde todas as crianças, meninos e meninas, aprendiam a ler e escrever em português, enquanto que os súditos de Abomé eram proibidos de frequentar as salas.

Os agudás - nesse momento um grupo composto pelos descendentes de negreiros, pelos escravos retornados, seus descendentes e seus escravos estão na origem de praticamente toda atividade econômica moderna e da penetração da cultura ocidental na região. Aliás, eles representavam na época o futuro, já que a cultura europeia - ou seja, suas "maneiras de branco" - acabaram por se impor a todos.

10 Elisée Reclus, na sua obra de 1887, observa que "nas famílias de cor (agudá) os casamentos consangüíneos, mesmo entre irmãos e irmãs de mães diferentes, são muito comuns e a opinião não os reprova” (apud Verger, 1953, p. 12). Entre as vinte filhas de Dom Francisco F. de Souza inventariadas por Souza (1992), onze se casaram com agudás em primeiras ou segundas núpcias; verificam-se, ainda, vários casos de consanguinidade, a saber: quatro filhos com tios ou primos, três filhos com sobrinhos, sete com irmãos e um caso entre pai e filha. 
Quando examinamos mais de perto a cultura agudá deste segundo momento, verificamos que ela é diferente daquela dos primeiros brasileiros. É diferente em si, mas, sobretudo, é a sua função social que muda. Os negreiros baianos eram brancos, portanto naturalmente diferentes dos nativos, de modo que tinham um lugar próprio na sociedade autóctone. Esse lugar era assegurado pela sua aliança econômica com o rei do Daomé e expresso simbolicamente pelo papel do Chachá e de outros "cabeceiras" brasileiros ${ }^{11}$ na estrutura de poder em exercício.

Os antigos escravos retornados, ao contrário, foram obrigados a inventar um lugar para si nessa sociedade que não os aceitava. Para ela, eles eram ao mesmo tempo aqueles que já tinham sido expulsos - vendidos como escravos - e estrangeiros - já que, ainda por cima, voltaram completamente diferentes, com "maneiras de branco". A construção de uma nova identidade social a partir da memória do tempo vivido no Brasil foi para eles o meio de se inserirem nessa sociedade, no mesmo lugar que já tinha sido estabelecido para os brancos. Como explica Meillassoux (1986, p. 105),

A noção de 'estrangeiro' é comum a todas as populações africanas. Geralmente é oposta à noção de 'homem', ou seja, de 'cidadão', de 'patrício', a pessoa provida de todas as prerrogativas sociais no meio considerado. [...] O estrangeiro deve se aliar a um protetor, seu avalista e sua 'testemunha' na sociedade onde ele penetra, laço prévio que permitirá o estabelecimento de todos os outros. Na falta deste aval, na solidão, o estrangeiro está fadado à servidão.

$\mathrm{Na}$ situação em análise, é exatamente a identidade "brasileira", já avalizada pelo rei Guêzo e por outros potentados, que garante os antigos escravos retornados e confere eficácia à sua estratégia de inserção social.

Eles tornam-se agudás, mas não exatamente como os outros. É verdade que eles tinham seus senhores como modelos e tinham assimilado grosseiramente a cultura deles, que era aproximadamente a dos primeiros agudás, mas eles tinham também trazido para a África uma certa cultura desenvolvida no Brasil pelas pessoas do povo e pelos próprios escravos. Foi assim que, afora a arquitetura e a representação de si, os indicadores de identidade "brasileira" mais visíveis remontam a práticas mais ligadas aos escravos do que a seus senhores no Brasil: é o caso da feijoada (originalmente um prato da senzala, antes de se transformar em prato nacional brasileiro), da festa de

11 Eram conhecidos como "cabeceiras" os comerciantes não africanos estabelecidos na região que ganhavam notoriedade. 
Nosso Senhor do Bonfim (primeiramente uma festa dos africanos e crioulos da Bahia, antes de se tornar motivo de devoção de todo um povo) e do folguedo da burrinha (festa popular de caráter folclórico que nunca foi verdadeiramente praticada pelas elites). A cultura agudá, primeiramente uma cultura à europeia, foi então se enriquecendo de aspectos de uma verdadeira cultura brasileira, tal como ela ia se construindo no próprio Brasil.

A presença colonial francesa, impondo "maneiras de branco" a todo o país, sustentou de certa maneira a opção cultural dessa massa de africanos genéricos retornados do Brasil. Aqueles que tinham partido como escravos voltaram como senhores, ou seja, portadores da cultura que se impunha no país. É nesse momento que a oposição entre as noções de "civilização/modernidade" e de "primitivismo/selvageria" adquire novos contornos no jogo de inserção dos antigos escravos na sociedade local.

E, assim, chegamos ao terceiro momento importante para compreendermos a identidade agudá no Benim, o período atual. Nos nossos dias, a memória do tempo vivido no Brasil cedeu lugar à memória das realizações feitas no Benim. Da mesma forma que a primeira memória teve como função permitir a inserção dos escravos retornados na sociedade local, a segunda teve também uma função social precisa. Na realidade, a oposição "escravos, gente importada" e "selvagens" continua na ordem do dia da interação social. É com base na memória das suas realizações ("nós fizemos tudo neste país...") que os "brasileiros" - excluídos de ofício enquanto escravos - defendem a legitimidade de seu lugar na sociedade beninense atual.

As relações entre os agudás e a administração francesa conheceram várias configurações. Os "brasileiros" foram primeiramente aliados dos franceses, que os utilizaram como intermediários em relação aos autóctones. Desde o primeiro momento, quando da instalação do protetorado de Porto Novo, em 1861, eles apoiaram decididamente a França contra a Grã-Bretanha (ver Costa e Silva, 1989a, p. 61-62). As grandes famílias de Porto Novo, por exemplo, chegaram a participar diretamente, ao lado dos franceses, do esforço de guerra contra Behanzin..$^{12}$ Ignacio Paraíso, o mais importante agudá de Porto Novo, foi o único africano a conseguir assento no Conselho da Colônia desde a sua instalação. Vários outros "brasileiros" foram diretamente empregados pela administração francesa em vários níveis (ver

12 O Rei Behanzin resistiu militarmente à ação colonizadora dos franceses. Tendo capitulado em 1894, morreu no exílio, na Argélia, em 1904. 
Sanvi, 1977). De certo modo, os "brasileiros" vivem ainda hoje este papel de intermediários, com pequenas variações. De fato, eles não podem assumir plenamente sua condição de agudás porque estabeleceram alianças com outros grupos étnicos através dos casamentos, o que os leva a uma situação de integração no seio das grandes famílias extensas, à africana; daí sua nova condição de intermediários.

Entretanto, na medida em que os franceses se assenhorearam do país, os "brasileiros" foram sendo progressivamente alijados das atividades economicamente mais rentáveis. Foi o caso primeiramente do comércio atacadista e, pouco depois, do comércio varejista, ambos colocados sob o monopólio das empresas francesas. Os comerciantes agudás mais solidamente estabelecidos foram assim levados à bancarrota.

A influência social e política dos "brasileiros" entra verdadeiramente em declínio a partir de 1946, quando a vida política e econômica do Benim muda radicalmente em função do novo sistema de representação política na Assembleia Territorial e na Assembleia Nacional francesa. É nesse momento, como explica o historiador beninense Karl Emmanuel Augustt (1995), que "os 'brasileiros' e os mestiços em geral, considerados como assimilados à administração colonial, são desalojados do poder". Essa tendência se acentuou ainda mais por ocasião da independência, quando os agudás, que já eram tradicionalmente considerados estrangeiros, foram então assimilados pelos beninenses aos franceses como colonizadores. "Eles são acusados de terem ajudado o branco, eles se colocaram desde o começo do lado do branco", resume outro historiador do Benin, o Prof. Adrien Djivo (1996). Karin Urbain da Silva, o cônsul honorário do Brasil, por sua vez, precisa que naquele momento houve um grande "acerto de contas" contra os "brasileiros", que durou até 1972 (Silva, 1996). Ele se refere ao regime marxista do General Kérekou, ${ }^{13}$ quando os agudás foram de novo discriminados, desta vez assimilados à burguesia. A despeito da participação de algumas personalidades na nomenclatura do regime, os "brasileiros" sustentam que foram praticamente banidos da vida pública nesse período, "vítimas da mesma fúria anticolonialista que tentou igualmente eliminar as chefias tradicionais". ${ }^{14}$

13 Atualmente Kérekou exerce o seu segundo mandato presidencial consecutivo depois da redemocratização de 1989.

14 A Sra. Patterson, aliás, chegou a ser presa com vários outros "brasileiros" por esse regime, sob acusação de atividades contrarrevolucionárias. 
Ao processo de democratização instalado em 1989 no Benim corresponde um movimento de revalorização das chefias tradicionais, bem como dos cultos vodus e demais manifestações religiosas. Um exemplo disso é o festival internacional das artes e das culturas voduns Ouidah 92, que teve lugar em janeiro de 1993 (ver Tall, 1995a e 1995b), e a instituição de um dia nacional do culto vodu, a ser comemorado justamente no mês de janeiro. A entronização de Honoré de Souza como oitavo sucessor de D. Francisco Félix de Souza, em outubro de 1995, vinte e seis anos depois da morte do último Chachá, não deixa de se inscrever nesse movimento que visa à valorização do peso político dos chefes tradicionais, entre os quais o Chachá.

É nesse contexto que podemos compreender a importância das cerimônias públicas muito mediatizadas que envolveram a entronização do Chachá VIII. Elas reforçam a memória das realizações, ao mesmo tempo em que reafirmam simbolicamente a aliança primitiva que deu aos agudás um lugar na sociedade daomeana. Sendo que, ainda por cima, pelo menos para a corte de Abomé, o Chachá é efetivamente considerado como o representante de todos os "brasileiros".

Vale ressaltar, a título de conclusão, que a bricolagem de uma nova identidade étnica permitiu a inserção social dos antigos escravos retornados na qualidade de cidadãos de plenos direitos. O presente estudo, por meio do uso de fontes orais e visuais, facilita o reconhecimento da continuidade do processo de representação de si como um instrumento de construção e afirmação da identidade étnica agudá. Além disso, possibilita também a atualização desse processo social por meio da valorização dos rituais e comportamentos propriamente "brasileiros" no âmbito da sociedade beninense, em pleno século XXI. Assim, as várias camadas de memória sustentam o patrimônio cultural dos agudás, num processo em que o passado afiança as relações sociais no presente.

\section{Referências}

ALMEIDA PRADO, J. F., 1954 [1950]. "Les relations de Bahia (Brésil) avec le Dahomey", in Revue d'Histoire des Colonies, Tomo XLI, segundo trimestre, pp. 167-226, Paris.

BOURDIEU, P. (Org.). Un art moyen: essais sur les usages sociaux de la photographie. Paris: Les Editions de Minuit, 1965. 
BRAGA, Júlio Santana. Notas sobre o "Quartier Brésil” no Daomé. Afro-Ásia, Salvador, 6-7, 1968.

CASTRO, Yêda Pessoa de. Notícia de uma pesquisa em África. Afro-Ásia, Salvador, n. 1, 1965.

COSTA E SILVA, Alberto. As relações entre o Brasil e a África Negra, de 1922 à primeira guerra mundial. In: . O vício da África e outros vícios, 1989a. p. 25-65.

. Francisco Felix de Souza, mercador de escravos. Rio de Janeiro: EDUERJ; Ed. Nova Fronteira, 2004.

1994.

. O Brasil, a África e o Atlântico no século XIX. Studia, Lisboa, n. 52, p. 195-220, . Os habitantes brasileiros de Lagos. In: O vício da África e outros vícios. Lisboa: Ed. João Sá da Costa, 1989b. p. 13-18.

. Os sobrados brasileiros de Lagos. In: O vício da África e outros vícios. Lisboa: Ed. João Sá da Costa, 1989c. p. 9-12.

. Um rio chamado Atlântico. Rio de Janeiro: Nova Fronteira, 2003.

CUNHA, Manuela Carneiro da. Etnicidade: da cultura residual mas irredutível. Revista de Cultura e Política, São Paulo, v. 1, n. 1, 1979.

. Introdução. In: CUNHA, Mariano Carneiro da. Da senzala ao sobrado. São Paulo: Nobel; Edusp, 1985a.

$1985 \mathrm{~b}$.

. Negros, estrangeiros: os escravos libertos e sua volta à África. São Paulo: Brasiliense,

FREUND, G. Photographie et société. Paris: Seuil, 1974.

FREYRE, Gilberto. "Acontece que são baianos". In: . Babia e baianos. Salvador: Fundação das Artes/Emp. Gráfica da Bahia, 1990.

GOFFMAN, E. La mise en scène de la vie cotidienne. Paris: Ed. De Minuit, 1973. (t. 1: La présentation de soi).

GURAN, M. Agudás: os "brasileiros" do Benim. Rio de Janeiro: Ed. Nova Fronteira; Ed. Gama Filho, 2000.

HAZOUMÉ, Paul. Le pacte de sang au Dahomey. Paris: Institut d'Ethnologie, 1937.

KRASNOWOLSKI, Andrzej. Les Afro-Brésiliens dans le processus de changement de la Côte des Escalves. Varsóvia: Ossolineum; Polskiej Akademii Nauk, 1987. 
LAW, Robin. Ouidab: the social history of a West African Slaving "port" - 1727-1892. Athens; Oxford: Ohaio University Presse; James Currey, 2004.

MEILLASSOUX, Claude. Anthropologie de l'esclavage: le ventre de fer et d'argent. Paris: Presses Universitaires de France, 1986.

RASSINOUX, Jean. Dictionnaire Français-Fon. Saint-Etienne: Imprimerie Dumas, 1987.

REIS, João José. Rebelião escrava no Brasil: a história do levante dos malês (1835). São Paulo: Brasiliense, 1987.

RODRIGUES, José Honório. The influence of Africa on Brazil and of Brazil on Africa. Journal of African History, III, I p. 49-67, 1962.

ROSSI, David A. The career of Domingos Martinez in the Bright of Benin - 1933-64 Journal of African History, VI, I, p. 79-90, 1965.

SANVI, Anne-Marie Clementine. Les métis et les Brésiliens dans la colonie du Dahomey 1880-1920. Dissertação (Mestrado em História) - Université Nationale du Bénin, Cotonu, 1977.

SOUZA, Simone de. La famille De Souza du Bénin-Togo. Cotonou: Les Editions du Bénin, 1992.

TALL, Emmanuelle Kadya. De la démocracie et des cultes voduns au Bénin. Cabiers d'Etudes Africaines, v. XXXV, n. 1, n. 137, 1995a.

. Dynamique des cultes voduns et du Christianisme Céleste au sud-Bénin. Cabiers des Sciences Humaines, v. 31, n. 4, 1995 b.

TURNER, Michel Jerry. Les Brésiliens: the impact of former Brazilian slaves upon Dahomey. Tese (Doutorado em História) - Boston University, Boston, 1975.

VERGER, Pierre. Influence du Brésil au Golfe du Bénin. Les Afro-Américains: Memoires de l'Institut Français de l'Afrique Noire, Dakar, n. 27, p. 11-101, 1953a.

. Flux et reflux de la traite de nègres entre le Golfe du Bénin et Babia de Todos os Santos du XVIIè. au XIXè. Siècles. Paris; La Haye: Mouton \& Co., 1968.

. Le culte des vodun d'Abomey aurait-il été apporté à Saint-Louis de Maranhon par la mère du roi Ghézo?. Les Afro-Américains: Mémoires de l'Institut Français de l'Afrique Noire, Dakar, n. 27, p. 157-160, 1953 b.

VERGER, Pierre Fatumbi. Entretien avec Emmanuel Garrides. L'Ethnographie (109), p. 167-178, 1991.

. Os libertos. São Paulo: Corrupio, 1992. 


\title{
Fontes orais
}

AUGUSTT, K. E. Entrevista concedida a Milton Guran, Cotonu, 4 set. 1995.

DJIVO, Adrien. Entrevista concedida a Milton Guran, Djeffa, 11 fev. 1996.

MEDEIROS, François. Entrevista concedida a Milton Guran, Paris, 28 jun. 1996.

PATTERSON, Francisca. Entrevista concedida a Milton Guran, Porto Novo, 12 fev. 1995.

POISSON, Émile. Entrevista concedida a Milton Guran, Pahou, 23 set. 1995.

RODRIGUES, Bruno. Entrevista concedida a Milton Guran, Bohicon, 14 fev. 1996.

SILVA, Karin U. da. Entrevista concedida a Milton Guran, Porto Novo, 10 fev. 1996.

SOUZA, Rachida de. Entrevista concedida a Milton Guran, Cotonu, 27 ago. 1995.

\begin{abstract}
Resumo: Este trabalho tem como proposta apresentar a pesquisa sobre os agudás desenvolvida desde 1994 no Benim e no Togo, na África Ocidental. Destaca-se o uso de fontes orais - como forma de constituir um corpus documental sobre as estratégias de organização da memória social dos agudás - e da fotografia - como instrumento de pesquisa para o estudo das formas de representação da identidade social. Enfatiza-se a pesquisa de campo realizada em 2010, quando se produziu um conjunto de registros audiovisuais e de fotografias com base no estudo dos processos de rememoração.
\end{abstract}

Palavras-chave: agudá, escravidão, Benim, identidade, fotografia, memória.

\section{Memory bricolage: oral and visual sources on the building of Agudá identity}

\begin{abstract}
The study presents a research about Agudá community that has been developed since 1994 in Benin and Togo, Western Africa. Noteworthy are the use of oral sources - in order to constitute a documental corpus on strategies of organizing the social memory of the Agudás and photography - as a research tool for the study of forms of representation of social identity. Finally, it is presented the results of the field research developed in 2010 when, based on the study of recollection processes, a set of audiovisual recordings and photographs were produced.
\end{abstract}

Keywords: agudá, slavery, Benin, identity, photography, memory.

Recebido em 30/01/2013

Aprovado em 14/05/2013 